\title{
Flow-Diversion Effect of LEO Stents: Aneurysm Occlusion and Flow Remodeling of Covered Side Branches and Perforators
}

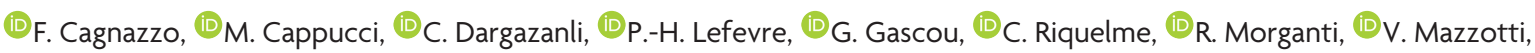 \\ (1)A. Bonafe, and 나. V. Costalat
}

\begin{abstract}
BACKGROUND AND PURPOSE: Flow diversion with intermediate-porosity stents (braided stents) has been recently reported for distally located small aneurysms. The aim of this study was to evaluate the flow-diversion effect of LEO stents on covered vessels and for aneurysms treated with sole stent-placement therapy.
\end{abstract}

MATERIALS AND METHODS: We retrospectively evaluated the following outcomes: 1) remodeling of covered side branches and perforators (extra-aneurysmal flow remodeling), and 2) the occlusion rate of aneurysms treated with sole stent-placement therapy (intraaneurysmal flow remodeling).

RESULTS: Seventy-six patients with 98 covered vessels were studied. Overall, 89 covered arteries (91\%) were normal, 7 showed narrowing $(7 \%)$, and $2(2 \%)$ were occluded $(1$ posterior communicating artery and $1 \mathrm{MCA}$ ) without related complications (mean DSA follow-up, 14 months). Univariate and multivariate analyses highlighted smoking $(P=.03)$ and the length of follow-up $(P=.002)$ as factors associated with arterial remodeling. Of the 17 Sylvian (lenticulostriate arteries) and 7 basilar perforators, 1 (4\%) group of Sylvian perforators covered with double stents had asymptomatic remodeling. Ten aneurysms (mean size, $3.5 \mathrm{~mm}$ ) were treated with LEO stents as stent monotherapy (5 recanalized after coiling and 5 directly treated with the LEO). Complete occlusion (Raymond-Roy I) was achieved in $70 \%$ of aneurysms (mean follow-up, 14 months). The Raymond-Roy I occlusion rate among recanalized aneurysms and those directly treated with LEO stents was $80 \%$ and $60 \%$, respectively $(P=.9)$.

CONCLUSIONS: The rate of flow remodeling on the covered arteries and perforators was $9 \%$ and $4 \%$, respectively, and was clinically irrelevant in all cases. Complete occlusion of aneurysms treated with sole stent-placement therapy was $70 \%$. These data stress the flow-diversion properties of LEO stents.

ABBREVIATIONS: PcomA = posterior communicating artery; $\mathrm{RR}=$ Raymond-Roy; $\mathrm{SAC}=$ stent-assisted coiling

EO stents (Balt Extrusion, Montmorency, France) are selfLexpanding closed-cell stents produced by braiding individual strands of nitinol onto a mandrel. ${ }^{1}$ Based on the braided morphology, LEO stents have a relatively small pore size (cell size of approximately $0.9 \mathrm{~mm}$ ) that gives a higher metal coverage ratio compared with other self-expandable stents, allowing a certain grade of flow-diverting hemodynamic effect. ${ }^{2}$ Accordingly, LEO

Received March 6, 2018; accepted after revision July 30.

From the Neuroradiology Department (F.C., M.C., C.D., P.-H.L., G.G., C.R., A.B., V.C.), University Hospital Güi-de-Chauliac, Centre Hospitalier Universitaire de Montpellier, Montpellier, France; and Section of Statistics (R.M., V.M.), University Hospital of Pisa, Pisa, Italy.

Please address correspondence to Federico Cagnazzo, MD, Neuroradiology Department, CHU Güi-de-Chauliac, 80 Ave Augustin Fliche, 34000 Montpellier, France; e-mail: f.cagnazzo86@gmail.com

Indicates article with supplemental on-line tables.

Indicates article with supplemental on-line photo.

http://dx.doi.org/10.3174/ajnr.A5803 stents have been recently reported as stent monotherapy for the treatment of small and complex intracranial aneurysms based on their flow-modification capacity and their biologic effects. ${ }^{3,4}$ The deployment of low-porosity flow-diverter stents across side branches or perforators has a potential risk of occlusion and related symptomatic ischemic lesions. ${ }^{5,6}$ Because of their intermediate porosity, braided stents could provide flow-change patterns similar to those provided by conventional flow-diverter devices, both on the aneurysm and covered side branches and perforators. ${ }^{3}$ However, the extra-aneurysmal flow modifications, the fate of vessels covered by LEO stents, and the related clinical sequalae have been poorly investigated in the literature.

We present a retrospective series of 76 intracranial aneurysms and 98 side branches covered by LEO stents with the aim of investigating the following: 1) the flow-diversion effect on the aneurysms treated with LEO stents as a stent monotherapy, 2) the flow remodeling of the covered side branches and perforators, and 3) the clinical events related to the flow changes on the investigated vessels. 


\section{MATERIALS AND METHODS}

\section{Patient Selection}

Our hospital institutional review board (Centre Hospitalier Universitaire de Montpellier) approved this retrospective study. Our institutional prospectively maintained data base (January 2011 to January 2018) was retrospectively reviewed by 2 and, in case of inconsistency, by 3 investigators independently. The inclusion criteria were the following: 1) intracranial aneurysms treated with a LEO placed across side branches or perforators, and 2) intracranial aneurysms treated with stent monotherapy in which LEO devices were used as intermediate-porosity flow diverters. Only patients examined with DSA at follow-up were included in this series. Flow diversion with the LEO as stent monotherapy was performed to treat the following: 1) small aneurysms with a complex morphology not amenable to simple coil embolization, balloon remodeling, or stent-assisted coiling (SAC); 2) distally located recanalized aneurysms requiring retreatment and difficult to treat with conventional coiling (for the unstable position of the microcatheter) or with flow diversion (for the presence of important branches or perforators); and 3) dissecting aneurysms not amenable to different treatments. The treatment strategy was chosen by multidisciplinary consensus (vascular neurosurgeons and interventional neuroradiologists).

\section{Antiplatelet Therapy}

For unruptured aneurysms, antiplatelet therapy included daily dual-antiplatelet medication with aspirin (Kardegic), $75 \mathrm{mg}$, and clopidogrel (Plavix), $75 \mathrm{mg}$, starting 5 days before treatment. The therapy was maintained for 3-6 months. Thereafter, based on the clinical and radiologic evaluation, the patients were switched to aspirin. VerifyNow P2Y12 assay (Accumetrics, San Diego, California) was used to test the platelet inhibition: both $\mathrm{P} 2 \mathrm{Y} 12$ reaction unit and aspirin reaction units were tested. When LEO stents were used in patients with acutely ruptured aneurysms, an intravenous bolus of abciximab $(0.125 \mathrm{mg} / \mathrm{kg})$ was administered a few minutes before stent deployment, and standard dual-antiplatelet therapy was started the day after. Concurrent with the procedure, in both unruptured and ruptured aneurysms, intravenous heparinization was performed (activated clotting time maintained above 250 seconds).

\section{Description of Technique}

All patients were treated under general anesthesia via a transfemoral approach. Through a long femoral sheath (triaxial approach), a 6F guiding catheter was advanced into the carotid or vertebrobasilar system. Vessels and aneurysms were analyzed via biplane and $3 \mathrm{D}$ rotational angiography. The LEO stent was unsheathed under roadmap guidance through the dedicated Vasco microcatheter (Balt). VasoCT (Philips Healthcare, Best, the Netherlands) with diluted iodinated contrast medium was used to assess stent apposition to the arterial wall. ${ }^{7,8}$

\section{Clinical and Imaging Assessment}

Usually, the angiographic follow-up was performed with MRA at 6 months and DSA at 12 and 24 months. Flow remodeling was examined with DSA. Flow remodeling was examined on the following arteries covered by LEO stents (On-line Table 1): ophthalmic artery, anterior choroidal artery, posterior communicating artery (PcomA), A1 segment (stent from the ICA to M1), A2 segment (stent from the A1 to the contralateral A2, or stent from the A1 to the ipsilateral A2 in cases of an absent or hypoplastic contralateral A1), callosomarginal and orbitofrontal arteries, middle cerebral artery (M2), superior cerebellar artery, anterior inferior cerebellar artery, and posterior cerebral artery. Covered anterior communicating arteries and related perforators were not considered in this study. Perforator arteries covered by the LEO were divided into 2 groups: Sylvian perforator (lenticulostriate arteries) and basilar artery perforators. Perforating arteries were grouped as 1 entity per case (group of perforators) and were counted accordingly. The native arterial configuration was based on preoperative angiography. The flow remodeling was recorded as follows: 1) normal artery (no change in flow or caliber), 2) reduced in caliber/ narrowing, and 3) occluded. Parent vessel stenosis was not considered as extra-aneurysmal flow remodeling. The ischemic complications related to covered vessels were detected on MR imaging at follow-up. Clinical follow-up information was obtained at the time of the follow-up clinic visits at 6,12 , and 24 months.

The aneurysm occlusion rate was defined on the basis of the Raymond-Roy (RR) classification: complete occlusion (class I), residual neck (class II), and incomplete occlusion or residual aneurysm (class III). ${ }^{9}$

\section{Statistical Analysis}

Categoric data were described by frequency, whereas quantitative data were described by mean and SD. The dependent variable was the angiographic outcome of the covered artery, and it was divided into "normal" and "occlusion/narrowing." The $\chi^{2}$ test was used to evaluate the qualitative risk factors for occlusion/narrowing (location, hypertension, smoking, number of stents, covered artery arising from the inner or outer curve or from a linear stent, and sex). The $t$ test (2-tailed) was applied to assess quantitative risk factors (length of follow-up and age). Although the number of events was $<20$, two variables (smoking and length of followup) were significantly associated with arterial occlusion/narrowing in univariate analysis and were analyzed together in a binary logistic regression (multivariate analysis) to assess the independent contribution of each risk factor. The results of the regression model were calculated by the Wald test and expressed using $P$ values and related odds ratios. All statistical analyses, descriptive and inferential, were performed with SPSS, Version 24 (IBM, Armonk, New York).

\section{RESULTS}

\section{Population Characteristics}

In the 7 -year period, 76 consecutive patients ( 51 women, 25 men; mean age, $54.5 \pm 10.5$ years) with 98 side branches and 24 groups of perforators (17 Sylvian perforators and 7 basilar perforators) covered with LEO stents were included in this study (details in On-line Tables 2 and 3). 

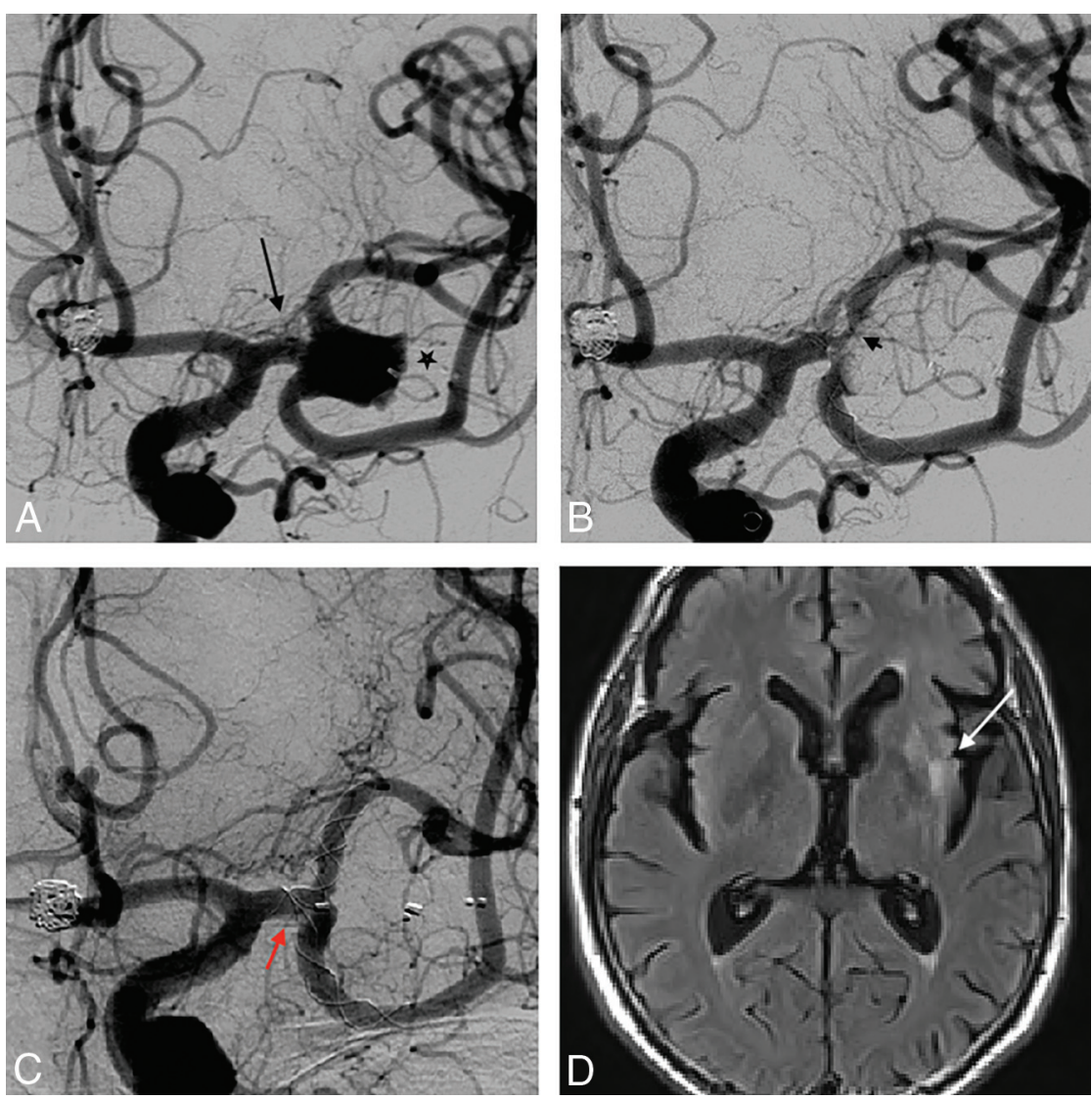

FIG 1. A, Procedural angiogram of a 63-year-old man showing a 9-mm left MCA aneurysm recanalized after treatment with a Woven EndoBridge (WEB; Sequent Medical, Aliso Viejo, California) device (black star). This image also shows the lenticulostriate arteries arising from the M1 (black arrow). B, The working projection demonstrates the implantation of 2 LEO stents ( $Y$-configuration) into the $\mathrm{M} 2$ branches and a second WEB into the aneurysm. There is a small incomplete wall stent apposition in the superior M2 branch, probably related to a small arterial dissection (short black arrow). C, A 13-month DSA image shows total occlusion of the aneurysm and remodeling of the lenticulostriate arteries covered with 2 overlapped LEOs (red arrow). D, MR imaging reveals small and asymptomatic ischemic lesions in the left basal ganglia (white arrow).

\section{Treatment-Related Complications}

Successful stent deployment was observed in all except 2 cases. A minor misopening of the proximal part of the stent was seen on plain $\mathrm{x}$-rays and confirmed by the VasoCT. Due to the minor malapposition of the stents, no additional maneuvers were performed and there were no related complications. Overall, in-stent acute thrombosis was seen in 9 cases and was completely resolved after abciximab injection in all except 1 case. Small and asymptomatic ischemic lesions in the basal ganglia were reported in 2 patients ( 1 case is described in Fig 1). Finally, there were 2 cases of asymptomatic ICA dissections.

Two cases of asymptomatic mild stent stenosis $(<50 \%)$ were observed and were related to in-stent intimal hyperplasia (1 case of mild stent stenosis is depicted in the On-line Figure).

\section{Angiographic Outcome of Covered Arteries and Perforators}

All of the included patients underwent DSA at follow-up (mean DSA follow-up, 14 months; median, 13.5 months; range, 11-24 months, IQR, 13-14 months). Overall, 76 (77.5\%) anterior circulation and $22(22.5 \%)$ posterior circulation side branches were covered with LEO stents (On-line Table 1). Among 15 patients, the superimposition of other arteries or bone structures hampered the angiographic visualization of some branching vessels that were not included in the analysis. During follow-up, 89 covered arteries (91\%) were normal, whereas 7 showed a reduction in diameter $(7 \%)$ (Figs 2 and 3 ) and 2 arteries (2\%) were occluded (Fig 3). There were no symptomatic or asymptomatic associated complications.

All except 1 group of perforators (17 Sylvian perforators and 7 basilar perforators) were patent at the last follow-up. One patient (4\%) with an MCA aneurysm treated with Y-stent placement had asymptomatic occlusion of some of the M1 perforators during 13 months of follow-up (Fig 1). The M1 perforators were covered with 2 overlapped LEOs.

\section{Factors Associated with Arterial Remodeling}

The factors tested as predictors of arterial occlusion/narrowing are reported in On-line Table 4. There was a trend toward lower mean age among patients presenting with flow remodeling (47.8 vs 54.7 years, $P=.06$ ). However, the univariate analysis showed that the only factors associated with an increased risk of arterial narrowing/occlusion were the length of radiologic follow-up $(P<.001$, OR $=1.85)$ and smoking $(P<.001$, OR $=18.4)$, which were confirmed with multivariate analysis (smoking: $\mathrm{OR}>20, P=.03$ ) (length of follow-up: OR $=1.99, P=.002)$.

\section{Angiographic Outcome of Aneurysms Treated with LEO Stents as Stent Monotherapy}

Overall, the LEO stent was used as flow-diversion treatment among 10 aneurysms (On-line Table 5). Five of them were recanalized after coiling ( 3 previously ruptured and 2 unruptured); the others were directly treated with LEO stents ( 4 unruptured aneurysms and 1 dissecting ruptured aneurysm) (Fig 3 and On-line Figure). Reasons behind the treatment with the sole stent-placement technique are detailed in On-line Table 5. The mean size of this group of aneurysms was $3.5 \mathrm{~mm}$ (median, $3.5 \mathrm{~mm}$; range, $2-5 \mathrm{~mm}$ ). Complete occlusion (RRI) was achieved in $70 \%$ of aneurysms. There were no differences in the size of aneurysms completely and incompletely occluded (RR III) $(P=.33)$. RR I occlusion was $60 \%$ and $80 \%$ among lesions directly treated with LEO stents versus aneurysms previously coiled, respectively $(P=.9)$. The mean length of follow-up was 14 months; the mean length of follow-up of the groups of completely occluded and incompletely occluded aneurysms was 22 months and 15 months, respectively $(P=.6)$.

AJNR Am J Neuroradiol 39:2057-63 Nov 2018 www.ajnr.org 

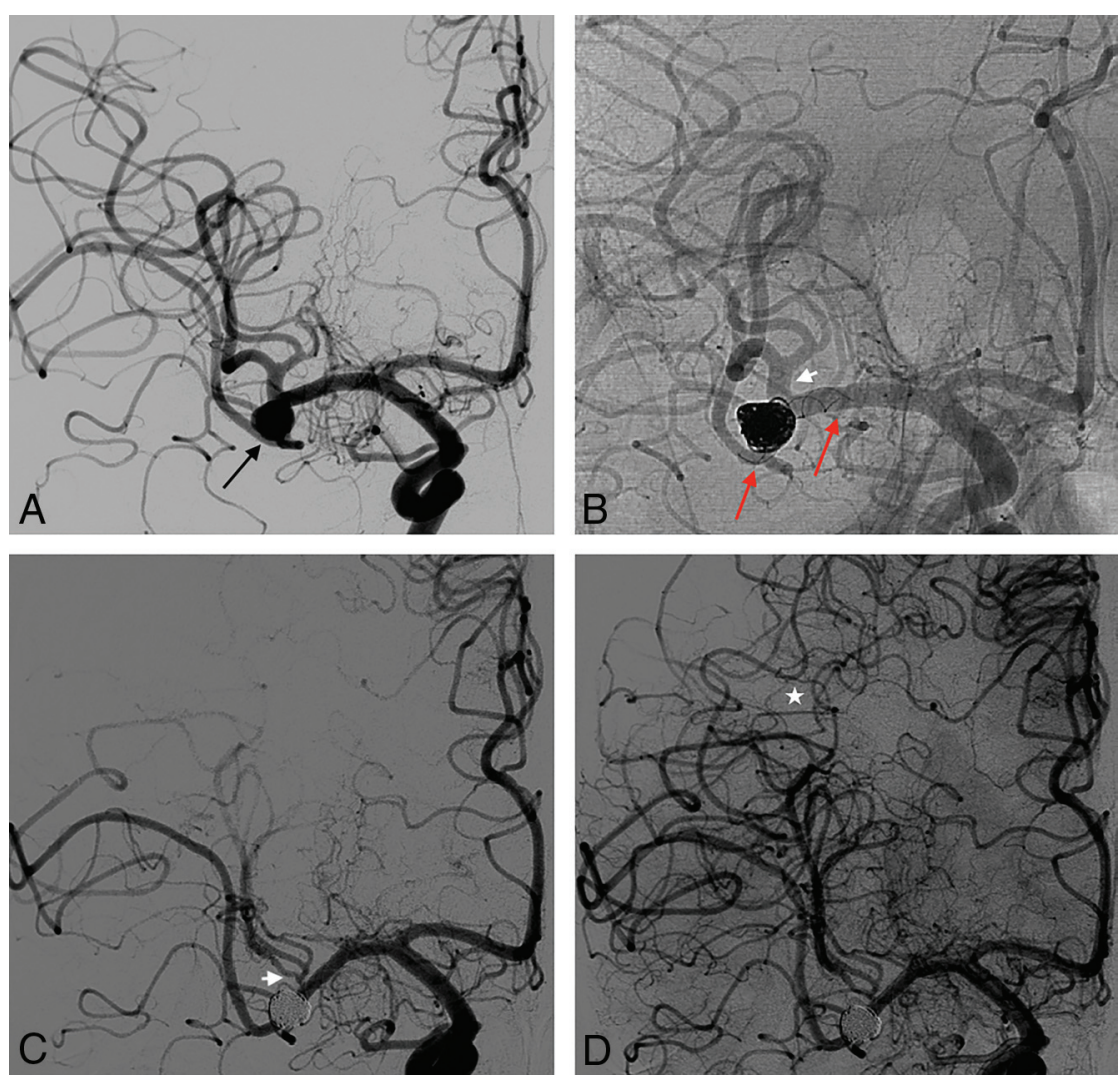

FIG 2. A, Procedural angiogram of a 49-year-old male patient with a 7-mm unruptured aneurysm on the right MCA bifurcation (black arrow). $B, A$ nonsubtracted angiographic image obtained during treatment demonstrates the successful SAC embolization of the aneurysm with a LEO stent $(2.5 \times 18 \mathrm{~mm})$ deployed from the M1 to the inferior M2 segment (red arrows). The M2 superior branch is covered by the stent (short white arrow). C, A 20-month follow-up DSA reveals complete aneurysm occlusion and asymptomatic narrowing of the covered superior $\mathrm{M} 2$ branch. $D$, Blood flow compensation is provided by the collateral circulation (white star).

\section{DISCUSSION}

Compared with laser-cut stents, LEO devices are braided from a single nitinol wire with closed cells that can change size on the basis of the stent deployment. ${ }^{10}$ The braided stents have relatively higher pore density $\left(0.979\right.$ and 0.782 pore $\left./ \mathrm{mm}^{2}\right)$ than the laser-cut stents $\left(0.276\right.$ pore $/ \mathrm{mm}^{2}$ for both Enterprise [Codman \& Shurtleff, Raynham, Massachusetts] and Neuroform [Stryker Neurovascular, Kalamazoo, Michigan] stents), giving greater metal coverage ( $14 \%$ for LEO stents versus $5 \%-10 \%$ for Enterprise and Neuroform stents). ${ }^{2}$ These characteristics may have important therapeutic implications. Indeed, although their metal surface coverage is lower than that in a flow diverter (30\% for the Pipeline Embolization Device; Covidien, Irvine, California), LEO stents have been successfully used as stent monotherapy, especially for distal and complex small aneurysms. ${ }^{3,11}$ In addition, computational fluid dynamics studies revealed that a double-overlapped braided stent resulted in greater flow diversion than a single Pipeline device, supporting the flow-diversion capacity of these stents. ${ }^{12}$ However, while the hemodynamic effect of flow diverters has been largely studied, the potential flow remodeling of LEO stents on the aneurysm, covered side branches, and perforator arteries has been poorly investigated.

\section{Angiographic Outcome of Covered Side Branches and Perforators}

To the best of our knowledge, our series is the first study that provides angiographic and clinical data about the perianeurysmal flow remodeling of LEO devices. The rates of arterial narrowing and occlusion were close to $7 \%$ and $2 \%$, respectively. Among series of flow diverters covering ICA branches, the rate of arterial occlusion and related symptoms ranged widely in relation to the type of covered artery. The rate of PcomA occlusion is reported between $7 \%$ and $50 \%$ without related symptoms and with lower rates of occlusion in the fetal variant (due to the major supply to the posterior cerebral artery). ${ }^{13-15}$ The rate of ophthalmic artery occlusion ranged from $0 \%$ to $17 \%$, with $<1 \%$ associated symptoms. ${ }^{16-19}$ Finally, occlusion of the anterior choroidal artery has been described between $0 \%$ to $5 \%$, without neurologic sequalae in most of the reported series. $^{20-22}$ Arterial occlusion and remodeling are influenced by the high density of the mesh. The pressure gradient across the jailed branch is reduced, and if the "flow competition" from the collateral supply is well-represented, the artery can be occluded. ${ }^{23}$ In our series, occlusion occurred in 1 PcomA (20\%) (Fig 3) and $1 \mathrm{MCA}$ (5\%), without related symptoms. In a recent meta-analysis of MCA aneurysms treated with flow-diverter stents, nearly $10 \%$ of jailed arteries were occluded during follow-up, with approximately $5 \%$ related neurologic events. ${ }^{24}$

Most interesting, in our series, the mean follow-up time among patients with arterial narrowing and occlusion was higher (19 and 21 months, respectively) compared with the group of normal arteries (13 months). Indeed, multivariate analysis confirmed the length of radiologic follow-up as an independent factor associated with arterial remodeling $(P=.002)$. Accordingly, it is likely that a longer follow-up time would demonstrate a higher incidence of vessel remodeling. In addition, arterial narrowing and occlusion were strongly related to smoking. Data regarding the influence of smoking on arterial occlusion after flow diversion are scant. In a series of 30 PcomAs covered with Pipeline devices, smoking was not a risk factor for occlusion in the multivariate analysis. ${ }^{13}$ Rouchaud et al, ${ }^{25}$ in a series of nearly 600 patients treated with the Pipeline, demonstrated that tobacco does not affect aneurysm occlusion or thromboembolic complications after flow diversion. However, other studies have shown that smoking is associated with worse clinical outcomes after stent treatment in other locations. In a study of 9000 patients undergoing percutaneous coronary implantation of drug-eluting stents, Matteau et $\mathrm{al}^{26}$ found that smoking was an independent risk factor for ischemic events and bleeding. Similarly, after percutaneous cor- 

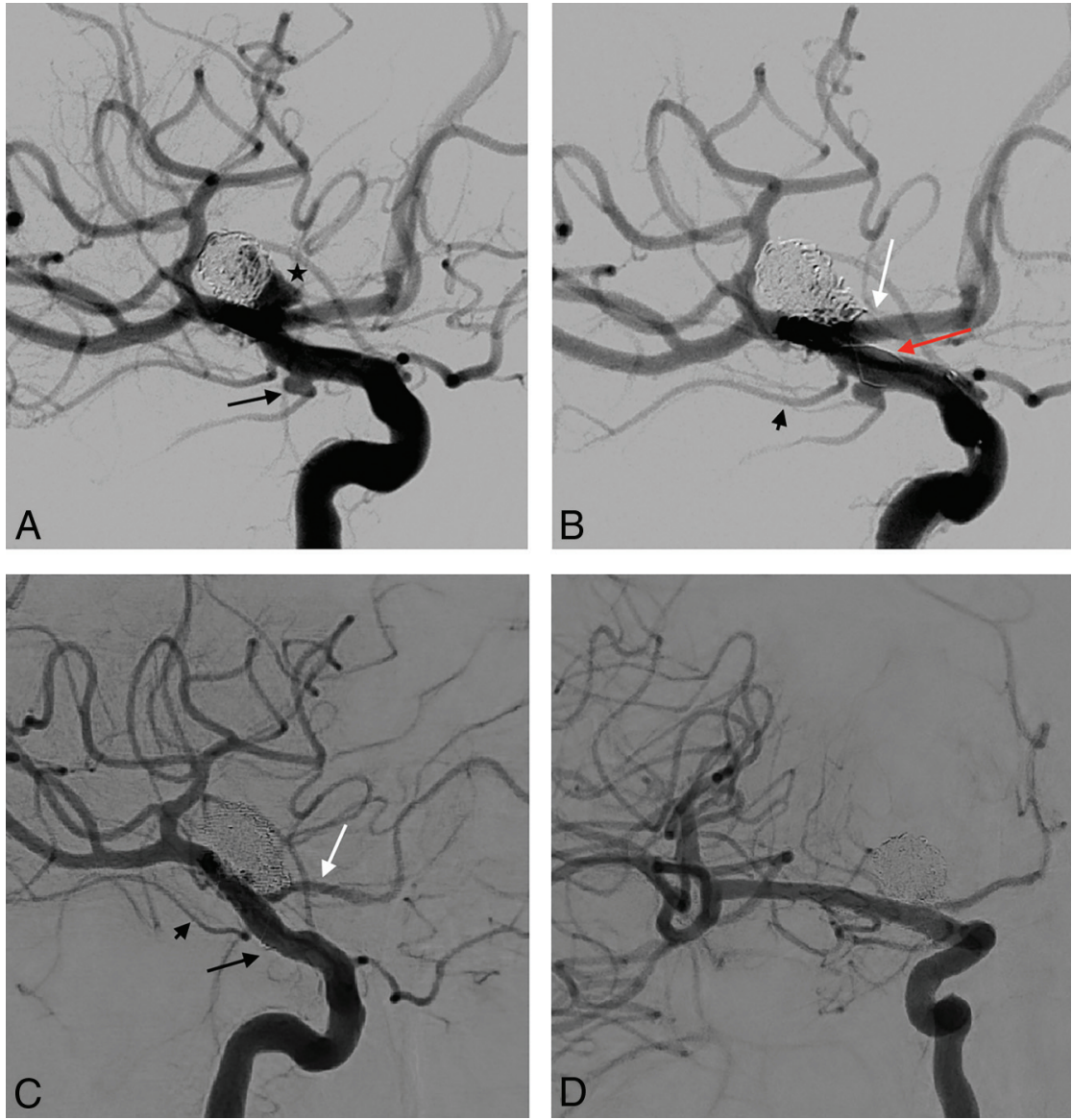

FIG 3. A, Procedural angiogram depicting a right, previously coiled, and recanalized ICA bifurcation aneurysm (black star), and a 3-mm PcomA aneurysm (black arrow). B, The ICA bifurcation aneurysm is treated with SAC with a LEO stent $(3.5 \times 18 \mathrm{~mm})$ implanted from the ICA to the MI (red arrow). The right $\mathrm{Al}$ (white arrow) and the right anterior choroidal artery (short black arrow) are covered by the stent. The PcomA artery and the small related aneurysm are covered with the LEO without additional coils. The working $(C)$ and frontal $(D)$ projections during a 24-month follow-up DSA demonstrate a small residual neck of the ICA bifurcation aneurysm (RR II), flow remodeling of the covered $\mathrm{Al}$ segment (white arrow), and occlusion of the PcomA artery and aneurysm (black arrow). The anterior choroidal artery is still patent (short black arrow).

onary intervention, Yeo et $\mathrm{al}^{27}$ found that active smoking was associated with a higher risk of in-stent thrombosis. After stent deployment, the cellular responses related to the mechanical vascular injury included the following: 1) platelet activation and inflammation, 2) granulation tissue and smooth-muscle cell proliferation, and 3) tissue remodeling and neoendothelialization. ${ }^{28}$ Smoking negatively influences the coagulation system, stimulating platelet aggregation, promoting a precoagulatory state, and causing endothelial dysfunction. ${ }^{27,28}$ These factors potentially stimulate an exuberant healing response leading to intimal hyperplasia at the level of the ostium of the branching arteries. Theoretically, this mechanism can explain the higher rate of occlusion of covered arteries in smoking patients found in our series.

Contrariwise, location, age, and sex were not statistically associated with arterial flow changes. Although few patients were treated with double LEO stents, multiple stents were not related to a higher risk of arterial occlusion. Similarly, multiple flow diverters were reported to be associated with greater occlusion in some series, ${ }^{18,29}$ while in other studies, the number of devices was not a significant predictor of sluggish flow. ${ }^{30}$ This result highlights the complexity of the flow-remodeling process, which involves the mechanical proper- ties of the stent as well as biologic (neoendothelialization) and hemodynamic factors (collateral circulation). ${ }^{14}$

In case of tortuous parent arteries (carotid siphon or bifurcations), the local stent deformation can influence the density of the pores, resulting in tighter mesh in the inner curves, with higher flow density and lower density of the pores in the outer curve. ${ }^{31}$ Rouchaud et $\mathrm{al}^{32}$ reported $75 \%$ optic nerve atrophy when the ophthalmic artery originated from the inner curve of the flow diverter, probably based on the higher local density of the stent. However, in our series, there was no statistically significant correlation between the different origins of the covered artery (from the inner or outer curve or from a linear stent) and the angiographic outcome.

Another important factor associated with flow diverters is the risk of perforating injury due to coverage of lenticulostriate or basilar perforators. Accordingly, flow-diversion treatment of MCA or posterior circulation aneurysms is associated with higher complications, mostly related to perforating injury. ${ }^{6,24,33,34}$ In our series, we observed only 1 case (4\%) of asymptomatic flow remodeling of lenticulostriate arteries covered with 2 overlapped LEO stents (Fig 1). Similarly, Aydin et $\mathrm{al}^{3}$ reported 1 patient with a small and clinically transient lacunar infarct in the basal ganglia due to Sylvian perforator occlusion during follow-up.

\section{Angiographic Outcome of Aneurysms Treated with the LEO Stent as Stent Monotherapy}

The first experience of flow-diverter treatment with LEO stents was described by Pumar et al, ${ }^{4}$ reporting $75 \%$ complete occlusion after treatment of 20 intracranial fusiform aneurysms. Recently, Aydin et $\mathrm{al}^{3}$ reported $73 \%$ complete occlusion of complex and small aneurysms located behind the circle of Willis and treated with braided stents as stent monotherapy. In our series, 70\% of aneurysms treated with the LEO as a flow diverter showed complete occlusion (RR I) during 14 months of follow-up, showing the flow-diversion capacity of these stents. We reported a slightly higher occlusion rate among aneurysms previously coiled (80\%) compared with lesions directly treated with sole stent-placement therapy $(60 \%)$. Stent monotherapy has also been reported with open-cell laser-cut stents. Fiorella et $\mathrm{al}^{35}$ reported 10 ruptured uncoilable aneurysms treated with Neuroform stents, showing $50 \%$ and $40 \%$ complete and near-complete occlusion, respectively. Comparable results reported by Nyberg and Larson ${ }^{36}$ showed a $45 \%$ complete or near-complete occlusion of small sac- 
cular aneurysms treated with a single low-porosity stent. Indeed, aneurysm occlusion is influenced by both the flow disruption of the intra-aneurysmal flow and the endothelialization of the stent with subsequent intravascular remodeling. ${ }^{35}$ The main factor influencing neoendothelialization is the vessel wall apposition of the stent; LEO devices, with their braided morphology, provide high conformability and wall apposition, promoting, together with their flow-diversion effect, thrombosis of the aneurysm. As with in vitro studies showing good conformability and vessel wall apposition, ${ }^{37}$ in our series, successful stent deployment and wall apposition were achieved in $97 \%$ of cases and were confirmed by the VasoCT. This outcome is in accordance with other recent series of LEO stent embolization reporting rates of successful stent delivery ranging from $90 \%$ to $100 \%$. $3,4,38$

\section{Limitations of the Study}

Our study has limitations intrinsic to single-center series. The data were analyzed retrospectively. The imaging outcome was assessed by operators and not independently. Although all patients received the same dual-antiplatelet therapy, the influence of the platelet responsiveness of each patient was not assessed in the univariate and multivariate analyses. Accordingly, we were not able to establish whether the platelet responsiveness was a risk factor of arterial narrowing/occlusion after stent coverage.

\section{CONCLUSIONS}

The rate of flow remodeling on the covered arteries and perforators was $9 \%$ and $4 \%$, respectively, and was clinically irrelevant in all cases. Flow changes on the covered side branches were directly related to the length of follow-up and influenced by smoking habits. Complete occlusion of aneurysms treated with sole stentplacement therapy was $70 \%$. These data stress the flow-diversion properties of LEO stents.

\section{ACKNOWLEDGMENTS}

We thank Beth De Felici for the English revision.

Disclosures: Pierre-Henri Lefevre-UNRELATED: Payment for Development of Educational Presentations: Balt, Medtronic, Stryker, MicroVention. Alain BonafeUNRELATED: Consultancy: Medtronic, Stryker, MicroVention. Vincent CostalatUNRELATED: Consultancy: Stryker, Balt; Grants/Grants Pending: Medtronic, MicroVention, Stryker*; Payment for Development of Educational Presentations: Medtronic, Stryker, Balt, MicroVention. *Money paid to the institution.

\section{REFERENCES}

1. Lubicz B, Kadou A, Morais R, et al. Leo stent for endovascular treatment of intracranial aneurysms: very long-term results in 50 patients with 52 aneurysms and literature review. Neuroradiology 2017;59:271-76 CrossRef Medline

2. Cho SH, Jo WI, Jo YE, et al. Bench-top comparison of physical properties of 4 commercially-available self-expanding intracranial stents. Neurointervention 2017;12:31-39 CrossRef Medline

3. Aydin K, Barburoglu M, Sencer S, et al. Flow diversion with lowprofile braided stents for the treatment of very small or uncoilable intracranial aneurysms at or distal to the circle of Willis. AJNR AmJ Neuroradiol 2017;38:2131-37 CrossRef Medline

4. Pumar JM, Arias-Rivas S, Rodriguez-Yanez M, et al. Using Leo Plus stent as flow diverter and endoluminal remodeling in endovascular treatment of intracranial fusiform aneurysms. J Neurointerv Surg 2013;5(Suppl 3):iii22-27 CrossRef Medline

5. Bhogal P, Ganslandt O, Bazner $\mathrm{H}$, et al. The fate of side branches covered by flow diverters: results from 140 patients. World Neurosurg 2017;103:789-98 CrossRef Medline

6. Gawlitza M, Januel AC, Tall P, et al. Flow diversion treatment of complex bifurcation aneurysms beyond the circle of Willis: a single-center series with special emphasis on covered cortical branches and perforating arteries. J Neurointerv Surg 2016;8:481-87 CrossRef Medline

7. Clarençon F, Di Maria F, Gabrieli J, et al. Clinical impact of flat panel volume CT angiography in evaluating the accurate intraoperative deployment of flow-diverter stents. AJNR Am J Neuroradiol 2017;38: 1966-72 CrossRef Medline

8. Poncyljusz W, Zwarzany L, Safranow K. Visualization of novel microstents in patients with unruptured intracranial aneurysms with contrast-enhanced flat panel detector CT. Eur J Radiol 2015;84: 1313-17 CrossRef Medline

9. Roy D, Milot G, Raymond J. Endovascular treatment of unruptured aneurysms. Stroke 2001;32:1998-2004 CrossRef Medline

10. Gross BA, Frerichs KU. Stent usage in the treatment of intracranial aneurysms: past, present and future. J Neurol Neurosurg Psychiatry 2013;84:244-53 CrossRef Medline

11. Lv X, Li Y, Jiang C, et al. Potential advantages and limitations of the Leo stent in endovascular treatment of complex cerebral aneurysms. Eur J Radiol 2011;79:317-22 CrossRef Medline

12. Wang C, Tian Z, Liu J, et al. Flow diverter effect of LVIS stent on cerebral aneurysm hemodynamics: a comparison with Enterprise stents and the Pipeline device. J Transl Med 2016;14:199 CrossRef Medline

13. Daou B, Valle-Giler EP, Chalouhi N, et al. Patency of the posterior communicating artery following treatment with the Pipeline Embolization Device. J Neurosurg 2017;126:564-69 CrossRef Medline

14. Vedantam A, Rao VY, Shaltoni HM, et al. Incidence and clinical implications of carotid branch occlusion following treatment of internal carotid artery aneurysms with the Pipeline embolization device. Neurosurgery 2015;76:173-78; discussion 178 CrossRef Medline

15. Brinjikji W, Lanzino G, Cloft HJ, et al. Patency of the posterior communicating artery after flow diversion treatment of internal carotid artery aneurysms. Clin Neurol Neurosurg 2014;120:84-88 CrossRef Medline

16. Yu SC, Kwok CK, Cheng PW, et al. Intracranial aneurysms: midterm outcome of Pipeline embolization device: a prospective study in 143 patients with 178 aneurysms. Radiology 2012;265:893-901 CrossRef Medline

17. Burrows AM, Brinjikji W, Puffer RC, et al. Flow diversion for ophthalmic artery aneurysms. AJNR Am J Neuroradiol 2016 Jun 2. [Epub ahead of print] CrossRef Medline

18. Chalouhi N, Daou B, Kung D, et al. Fate of the ophthalmic artery after treatment with the Pipeline Embolization Device. Neurosurgery 2015;77:581-84; discussion 584 CrossRef Medline

19. Griessenauer CJ, Ogilvy CS, Foreman PM, et al. Pipeline Embolization Device for small paraophthalmic artery aneurysms with an emphasis on the anatomical relationship of ophthalmic artery origin and aneurysm. J Neurosurg 2016;125:1352-59 CrossRef Medline

20. Brinjikji W, Kallmes DF, Cloft HJ, et al. Patency of the anterior choroidal artery after flow-diversion treatment of internal carotid artery aneurysms. AJNR Am J Neuroradiol 2015;36:537-41 CrossRef Medline

21. Raz E, Shapiro M, Becske T, et al. Anterior choroidal artery patency and clinical follow-up after coverage with the Pipeline embolization device. AJNR Am J Neuroradiol 2015;36:937-42 CrossRef Medline

22. Rangel-Castilla L, Munich SA, Jaleel N, et al. Patency of anterior circulation branch vessels after Pipeline embolization: longer-term results from 82 aneurysm cases. J Neurosurg 2017;126:1064-69 CrossRef Medline

23. Saleme S, Iosif C, Ponomarjova S, et al. Flow-diverting stents for intracranial bifurcation aneurysm treatment. Neurosurgery 2014; 75:623-31; quiz 631 CrossRef Medline

24. Cagnazzo F, Mantilla D, Lefevre PH, et al. Treatment of middle ce- 
rebral artery aneurysms with flow-diverter stents: a systematic review and meta-analysis. AJNR Am J Neuroradiol 2017;38:2289-94 CrossRef Medline

25. Rouchaud A, Brinjikji W, Cloft HJ, et al. Smoking does not affect occlusion rates and morbidity-mortality after Pipeline embolization for intracranial aneurysms. AJNR Am J Neuroradiol 2016;37: 1122-26 CrossRef Medline

26. Matteau A, Yeh RW, Camenzind E, et al. Balancing long-term risks of ischemic and bleeding complications after percutaneous coronary intervention with drug-eluting stents. Am J Cardiol 2015;116: 686-93 CrossRef Medline

27. Yeo KK, Armstrong EJ, Soni K, et al. Long-term outcomes of angiographically confirmed coronary stent thrombosis: results from a multicentre California registry. EuroIntervention 2015;11:188-95 CrossRef Medline

28. Inoue $\mathrm{T}$, Croce $\mathrm{K}$, Morooka $\mathrm{T}$, et al. Vascular inflammation and repair: implications for re-endothelialization, restenosis, and stent thrombosis. JACC Cardiovasc Interv 2011;4:1057-66 CrossRef Medline

29. Puffer RC, Kallmes DF, Cloft HJ, et al. Patency of the ophthalmic artery after flow diversion treatment of paraclinoid aneurysms. J Neurosurg 2012;116:892-96 CrossRef Medline

30. Durst CR, Starke RM, Clopton D, et al. Endovascular treatment of ophthalmic artery aneurysms: ophthalmic artery patency following flow diversion versus coil embolization. J Neurointerv Surg 2016;8: 919-22 CrossRef Medline

31. Makoyeva A, Bing F, Darsaut TE, et al. The varying porosity of braided self-expanding stents and flow diverters: an experimental study. AJNR Am J Neuroradiol 2013;34:596-602 CrossRef Medline

32. Rouchaud A, Leclerc O, Benayoun Y, et al. Visual outcomes with flow-diverter stents covering the ophthalmic artery for treatment of internal carotid artery aneurysms. AJNR Am J Neuroradiol 2015; 36:330-36 CrossRef Medline

33. Kallmes DF, Hanel R, Lopes D, et al. International retrospective study of the Pipeline embolization device: a multicenter aneurysm treatment study. AJNR Am J Neuroradiol 2015;36:108-15 CrossRef Medline

34. Wang CB, Shi WW, Zhang GX, et al. Flow diverter treatment of posterior circulation aneurysms: a meta-analysis. Neuroradiology 2016;58:391-400 CrossRef Medline

35. Fiorella D, Albuquerque FC, Deshmukh VR, et al. Endovascular reconstruction with the Neuroform stent as monotherapy for the treatment of uncoilable intradural pseudoaneurysms. Neurosurgery 2006;59:291-300; discussion 291-300 CrossRef Medline

36. Nyberg EM, Larson TC. Beneficial remodeling of small saccular intracranial aneurysms after staged stent only treatment: a case series. J Stroke Cerebrovasc Dis 2014;23:80 - 85 CrossRef Medline

37. Valdivia y Alvarado M, Ebrahimi N, Benndorf G. Study of conformability of the new LEO Plus stent to a curved vascular model using flat-panel detector computed tomography (DynaCT). Neurosurgery 2009;64:ons130-134; discussion ons134 CrossRef Medline

38. Machi P, Costalat V, Lobotesis K, et al. LEO Baby Stent use following balloon-assisted coiling: single- and dual-stent technique-immediate and midterm results of 29 consecutive patients. AJNR Am J Neuroradiol 2015;36:2096-103 CrossRef Medline 